\title{
GÊNERO E RAÇA NA CONTEMPORANEIDADE: Um diálogo entre Silva Rivera Cusicanqui e a Marcha Mundial Das Mulheres
}

\section{Suzielen Taiane das Graças ${ }^{1}$}

\section{Resumo}

Este artigo objetiva analisar como o movimento social contemporâneo Marcha Mundial das Mulheres lida com a categoria raça e classe, e com as especificidades das mulheres subalternas. Já em sua primeira edição (em 2000), a Marcha se tornou um importante espaço de luta e empoderamento de mulheres, bem como uma ferramenta de pressão para dar visibilidade às demandas feministas frente ao Estado e ao cenário internacional. Como um movimento transnacional, a MMM aglutina e condensa demandas, podendo assim resultar em uma categorização generalizada e única das reivindicações das mulheres. Através da teórica Silvia Rivera Cusicanqui, busca-se compreender como a MMM, enquanto movimento advindo de um país desenvolvido insere pautas eurocêntricas na realidade latino-americana e como as mesmas são fomentadas e adequadas às mulheres que sofrem com a exclusão patriarcal e colonial. Com contribuições da teórica Silvia Rivera Cusicanqui, como a Sociologia da Imagem, o artigo busca lançar luz à necessidade de atentar-se à grande diversidade e diferentes concepções de mundo na constituição dos movimentos sociais [feministas] transnacionais.

Palavras-chave: Feminismo - Colonialismo/colonialidade - Movimentos sociais.

\section{Abstract}

This article analyzes how the contemporary social movement "World March of Women" deals with the factor of race and class and with the specifics of the subaltern women. Already in its first edition (in 2000), the March became an important space of struggle and empowerment for women, as well as a pressure mechanism to give visibility to feminist demands before the state and the international scene. As a transnational movement, MMM gathers and condenses demands, which can result in a general and single categorization of the claims of women. Through the theory of Silvia Rivera Cusicanqui, we seek to understand how the MMM, as a movement arising from a

\footnotetext{
${ }^{1}$ Bacharela em Relações Internacionais pela Universidade Federal da Grande Dourados (UFGD), grau obtido em dezembro de 2014. Atualmente, a autora cursa o mestrado no Programa de Pós-Graduação em Integração Contemporânea da América Latina na UNILA. Bolsista do Programa de Demanda Social-Pró-reitoria de Pesquisa e Pós-Graduação - Unila, PRPPG, Brasil.
} 
developed country, brings in Eurocentric agendas into the Latin American reality, and how they are promoted and adequate for women who suffer from patriarchal and colonial exclusion. With contributions from theory of Silvia Rivera Cusicanqui, and the Sociology of the Image, the article seeks to shed light to the need of being aware of the great diversity and the different world views in the constitution of the [feminist] transnational social movements.

Keywords: Feminism - Colonialism - Social movements.

\section{Inntrodução}

O presente artigo é fruto de anseios pessoais da autora, bem como de sua trajetória de pouco mais de um ano de iniciação científica, realizada no grupo de pesquisa "A tradução do Subalterno no projeto epistêmico político na América Latina", formado por professores e alunos de Relações Internacionais da Universidade Federal da Grande Dourados. A autora possuía inquietações em relação à abordagem do gênero nas Relações Internacionais, assim como as demais categorias de exclusão das mulheres nesse campo do conhecimento.

No decorrer do trabalho, através de estudos sobre teorias, conceitos e questões póscoloniais que de forma limitada se inserem nas Relações Internacionais, apontam-se reflexões acerca da condição subalterna das mulheres na América Latina e, como por meio da colonialidade essas mulheres, mesmo nos espaços de luta, não conseguem uma emancipação total das opressões e dominações herdadas dos tempos coloniais.

Com a globalização ${ }^{2}$ e a dinamização das relações sociais, que com maior facilidade passaram a um patamar global, ocorreram transformações na programação e articulação dos movimentos sociais. Essas mudanças desembocaram na transnacionalização de diversos movimentos sociais que levam pautas e demandas locais para o cenário de reivindicação global.

$\mathrm{Na}$ solidificação e expansão desses movimentos sociais transnacionais ocorre a exportação de suas pautas para diferentes partes do mundo, ou seja, as demandas locais

\footnotetext{
${ }^{2}$ A produção teórica sobre os movimentos sociais no novo milênio defronta-se com novas demandas, novos conflitos e novas formas de organização, todos gerados pelas mudanças ocorridas nas últimas décadas do século XX, genericamente circunscritas como efeitos da globalização, em suas múltiplas faces (GOHN, 2008, p. 442). Nesse texto utilizaremos globalização como "o ápice do processo de internacionalização do mundo capitalista" (SANTOS, 2001, p. 12) escolhendo como marco temporal os acontecimentos na virada do século XX para o século XXI, pontuando aqui o aumento das interações e trocas por meio das redes globais, uma ampla abertura das fronteiras - sem a extinção das mesmas - para livre circulação de bens e capital resultante da pressão sobre os governos para tal abertura e dos avanços tecnológicos (WALLERSTEIN, 2005, p. 67 e 74).
} 
passam por um processo que as condensa no espaço de discussão global, no qual se elencam os principais pontos de luta e retornam aos espaços nacionais. Nesse continuum, as pautas são fortalecidas como demandas universais, mas deve-se atentar para a perda das especificidades das lutas locais. A Marcha Mundial das Mulheres como um movimento social contemporâneo e transnacional se insere nessa lógica de universalização de demandas.

Este artigo está dividido em quatro partes para além desta introdução, primeiramente apresenta-se uma breve contextualização do Feminismo nas Relações Internacionais, a segunda parte versa sobre as questões de gênero e raça na colonialidade, bem como as pautas feministas na América Latina e seus diferenciais. Na terceira parte analisa-se como a Marcha Mundial das Mulheres, enquanto movimento social, trabalha e desenvolve as questões de raça e suas especificidades. Na quarta e última parte apresentam-se as considerações finais.

\section{Breve contextualização do feminismo nas Relações Internacionais}

Os debates entre correntes de pensamentos distintos permeiam toda a esfera da disciplina de Relações Internacionais (RI), sendo o primeiro grande debate da disciplina entre os idealistas e realistas; o segundo debate ocorre entre tradicionalistas e behavioristas; já o terceiro debate - conhecido também como inter-paradigmático - entre os neorrealistas, transnacionalistas e radicais. O quarto, e último, debate é pontuado por argumentações trocadas entre racionalistas e reflexivistas, que abriu espaço para um novo movimento na disciplina como resultado de seu fortalecimento na década de 1990 (SODUPE, 2003, p. 17). Nas RI desenvolveram-se oportunidades para o diálogo com diferentes áreas do conhecimento, com isso, temas para além dos tradicionais começaram a ser inseridos - ainda que de forma marginalizada - na realidade desse campo.

Um dos novos temas inseridos nas RI foi a questão de gênero fomentada pelos coletivos e movimentos feministas. Entretanto, a luta feminista vem de muito antes, "no século XVIII baseando-se em teorias iluministas muitas mulheres reivindicavam direitos e buscavam a emancipação feminina" (PINSKY \& PEDRO, 2008, p. 266). Na disciplina o feminismo aparece no final da década de 1980, logrando um maior espaço e inserção a partir dos anos 1990, por meio da ampliação temática e epistemológica oferecida pelo surgimento das perspectivas pós-positivista/reflexivista.

O feminismo em sua forma mais expressiva surgiu no final do século XIX, em sua primeira etapa reivindicava-se voto, educação e direito à propriedade para as mulheres. Nos 
anos 1970 o feminismo começou a lutar - também - por cidadania plena para as mulheres, através de direitos sociais mais amplos. Essas duas etapas articuladas no Ocidente estavam majoritariamente vinculadas ao Estado. A terceira etapa ultrapassou as fronteiras ocidentais e firmou-se sobre questões que demandavam igualdade de gênero, a partir dos anos 1980.

\begin{abstract}
A terceira geração, que passou a abarcar feministas na disciplina de Relações Internacionais, também tem sido menos centrada no Ocidente e mais inclusiva na sua agenda. As conferências das Nações Unidas da década de 1990 são reveladoras da mudança a esse respeito: tanto em Pequim quanto no Cairo, [...] (NOGUEIRA; MESARI, 2005, p. 224-225)
\end{abstract}

Sendo o feminismo uma teoria nascente e distante dos aportes clássicos, encontra forte resistência e muitos obstáculos em seu desenvolver no campo das RI. Toda produção de conhecimento que utiliza a variável gênero é subsumida - de forma impositiva - pelas correntes dominantes dessa disciplina (SODUPE, 2003, p. 197-198).

As principais correntes da disciplina se colocam como voz da sociedade, homogeneizando assim o discurso, invisibilizando as especificidades das mulheres e dos demais indivíduos marginalizados. Toda a base teórica das RI foi construída e solidificada nessa dinâmica de representação e tutela - que converge na subordinação, principalmente, no que se refere às mulheres - dos mais frágeis, impossibilitando a atuação dos mesmos em espaços vitais para seu desenvolvimento político-social.

Como já citado, a luta das mulheres por direitos não se configura como algo contemporâneo e recente, porém, especificamente nas RI, as pautas feministas só conseguiram espaço diante das crescentes dificuldades das teorias dominantes em lidar com as questões de gênero que se evidenciavam cada vez mais - o estupro utilizado como arma de limpeza étnica/guerra foi um dos sinais de alerta para a disciplina que não teve mais como não lidar com a importância da variável gênero na política internacional (NOGUEIRA; MESSARI, 2005, p. 223).

Com a conquista desse espaço na disciplina, a teoria feminista passa a analisar os conceitos fundamentais para tal campo, bem como a masculinização desses conceitos. Antes da virada deste século, as feministas estudavam e analisavam principalmente temas relacionados à economia e segurança, não se atentando a outros temas tão importantes quanto para a vida das mulheres. A teoria criticava os diferentes impactos dos principais conceitos abordados nas RI sobre homens e mulheres, e também nas relações de gênero, a partir disso criam-se novas questões e demandas para a realidade internacional. A principal questão 
tratada pelo feminismo, herdada do Iluminismo, é a emancipação, aproximando assim o feminismo à teoria crítica (SODUPE, 2003, p. 197).

Entretanto, o feminismo é muito plural e diverso quando se trata de aproximações e similaridades teóricas. Essa vasta diversidade teórica é algo importante para sua construção e produção de conhecimento. Um dos campos no qual tal teoria se desenvolve possui caráter normativo - posicionando-se como corrente reflexivista - pois propõe mudanças para o status $q u o$ das Relações Internacionais. O feminismo enquanto teoria questiona as bases ontológicas e epistemológicas das Relações Internacionais, pois as mesmas não dialogam como as perspectivas de gênero ou com os indivíduos marginalizados na sociedade.

Es interesante mencionar que el feminismo en las Relaciones Internacionales está contribuyendo a que los derechos de las mujeres tengan un perfil cada vez más acusado en el discurso internacional sobre los derechos humanos. (SODUPE, 2003, p. 200). ${ }^{3}$

Em meio à variedade teórica do feminismo nas RI - feminismo crítico, feminismo construtivista, feminismo liberal, feminismo pós-moderno - o artigo adota a postura do feminismo pós-colonial, no qual se tomará por base a indissociação das categorias raça, gênero e classe. Tal escolha é motivada pelo interesse em estudar a realidade latino-americana a partir de intelectuais oriundas desse continente.

Infelizmente, ainda existem poucos espaços e estudos sobre feminismo pós-colonial, mesmos os teóricos da perspectiva decolonial ${ }^{4}$ não dedicam tempo às análises sobre relações de gênero e suas implicações e influências no sistema colonial-patriarcal. Esses estudiosos não reconhecem - com exceção de Maria Lugones, que lida com as questões de gênero e sua intersecção com diferentes categorias excludentes - a importância dessa variável para o desenvolvimento real da América Latina e a construção de um projeto decolonial.

O feminismo, até os anos 2000, estava muito voltado para questões de segurança e economia, temas tidos como de primeira ordem e tradicionais para as análises de Relações Internacionais. Após esse período houve, como já citado, a pluralização das perspectivas teórico-construtivistas, dessa pluralização surgem as feministas pós-coloniais que trabalham e desenvolvem temas que estão à margem das análises tradicionais. As feministas pós-coloniais não deixaram de lado as principais pautas que aquecem os debates no cenário internacional, as

\footnotetext{
${ }^{3}$ Tradução livre: É interessante mencionar que o feminismo nas Relações Internacionais está contribuindo para que os direitos das mulheres tenham um perfil cada vez mais acentuado no discurso internacional sobre os direitos humanos.

${ }^{4} \mathrm{O}$ grupo Modernidade/Colonialidade surgiu no século XX e possui como projeto a decolonização do saber, ser, poder, natureza e gênero. Formado por intelectuais como Walter Mignolo, Aníbal Quijano e Boaventura de Souza Santos, evidencia que a colonialidade é a parte obscura da modernidade.
} 
mesmas incluíram e se focaram em outras categorias de análises contemplando a diversidade e a pluralidade existentes em seu campo de estudos. Em meio à diversidade teórica em construção do feminismo nas Relações Internacionais, a perspectiva Pós-colonial busca elucidar as relações internacionais de modo abranger categorias que são descartadas pelo mainstrean do campo.

O Feminismo Pós-Colonial interpreta a realidade internacional a partir da intersecção entre cultura, classe social, raça e localização geográfica. Tecendo críticas ao feminismo ocidental e sua pretensão de universalidade, Mohanty (1988) defende que a emancipação da mulher é condicionada espaço-temporalmente, o que gera distintas formas de agência política e subordinação feminina (MASO; GAHLERA, p. 4. [No prelo]).

Em meio a esse vazio, destacamos os estudos e interpretações de Silvia Rivera Cusicanqui, historiadora e socióloga Aymara-boliviana que busca tornar o conhecimento múltiplo, através da Sociologia da Imagem, na qual se aprecia e se considera todas as formas de produção de conhecimento e não apenas a palavra escrita. Silvia faz parte dos grupos de ativismo indigenista Katarista e dos cultivadores de coca. Através de seu ativismo e da união com outros intelectuais indígenas e mestiços criou a Oficina de História Oral Andina (em 1983), tal grupo lidava com questões de identidade, historicidade e movimentos sociais indígenas por meio da oralidade. A mesma é autora de vários livros, como "Ch'ixinakax utxiwa: Una reflexión sobre prácticas y discursos descolonizadores", "Oprimidos pero no vencidos", Violencias [Re] encubiertas em Bolivia", entre outros. É professora da Universidad Mayor de San Andrés de La Paz, tendo sido professora convidada de diferentes universidades em outros países.

A autora do presente artigo compartilha semelhante postura crítica referente à lacuna existente entre os estudos de Relações Internacionais e a prática social, no sentido de não haver um diálogo substancial com a realidade social. As perspectivas latino-americanas são pouco estudadas nas Relações Internacionais, autoras como Silvia R. Cusicanqui têm muito a contribuir com o feminismo pós-colonial estudado no âmbito das RI.

Fundamentação teórico-metodológica: Gênero e raça na colonialidade e as possibilidades interpretativas da sociologia da imagem

Silvia R. Cusicanqui propõe uma reformulação nos modos de produção de conhecimento, mais precisamente, no modo de conceber e aceitar o conhecimento nas suas mais variadas e distintas formas, uma vez que há uma predominância da produção de 
conhecimento escrita em detrimento das outras. Para a autora através de música, teatro, imagens, desenhos, etc. também se produz conhecimento, este tão válido e importante quanto o escrito.

A Sociologia da Imagem se configura como um método pedagógico de percepção e aprendizado que busca ligar novamente todos os sentidos humanos e fazer com que estes trabalhem conjuntamente na formação e concepção do conhecimento. A proposta é que se dê maior atenção a todas as formas de produzir conhecimento e de expressão, deixando de lado o protagonismo isolado da forma textual de produção intelectual.

Las imágenes tienen la fuerza de construir una narrativa crítica, capaz de desenmascarar las distintas formas del colonialismo contemporáneo. Son las imágenes más que las palabras, en el contexto de un devenir histórico que jerarquizó lo textual en detrimento de las culturas visuales, las que permiten captar los sentidos bloqueados y olvidados por la lengua oficial. (CUSICANQUI, 2010a, p. 5). ${ }^{5}$

A Sociologia da Imagem pretende-se como um método que se diferencie das formas dominantes na produção de conhecimento, procura meios de olhar a realidade de forma horizontal. A hierarquização da palavra escrita foi uma das mais importantes ferramentas utilizadas para invisibilizar a cultura dos povos indígenas latino-americanos. Foi através dessa hierarquização que os modos de produção de conhecimento, de comunicação e de relacionamento foram se transformando, deixando de lado as tradições culturais e se adaptando a vida civilizada dos povos ocidentais, tais mudanças ocorreram, em grande parte, impositivamente.

Nesse contexto a situação das mulheres latino-americanas se difere da história das anglo-saxãs, por exemplo, pois a sua região é marcada pela subordinação e exploração da época colonial (CAROSIO, 2012). O povo latino-americano como um todo sofreu com as mazelas coloniais - e ainda sofre com suas heranças - ou seja, as marcas deixadas pela dominação, subjugação e opressão, ainda configuram sua realidade. Contudo, a América Latina $^{6}$ vai se desenvolvendo na medida em que sua população começa a lutar contra a

\footnotetext{
${ }^{5}$ Tradução livre: As imagens tem a força de construir uma narrativa crítica, capaz de desmascarar as diferentes formas do colonialismo contemporâneo. São as imagens mais que as palavras, no contexto de um devir histórico que hierarquizou o texto em detrimento das culturas visuais, as que permitem captar os sentidos bloqueados e esquecidos pela língua oficial.

${ }^{6}$ Utiliza-se aqui a noção América Latina levando em conta seu caráter heterotópico, como comunidade de destino. "O Termo América Latina é uma representação ideológica, pois, se afirma na linha de constituição das sociedades nacionais e no avanço do processo pós-colonial na região, contudo é heterotópico na medida em que sua possibilidade como uma comunidade de destino significa a invenção de outro espaço que não está previsto na continuidade do projeto colonial, que era ontologicamente incapaz de fundar uma comunidade de origem" (MARTINS, 2012, p. 14. Tradução livre).
} 
opressão e exploração advindas de seus eternos protetores, os países desenvolvidos, as metrópoles, que acima de tudo busca[va]m propagar a evolução e o desenvolvimento por meio do projeto civilizatório.

\begin{abstract}
América Latina colonial nunca fue una comunidad de origen, solo una empresa de exploración y expropiación. El término incluso constituye una violencia simbólica y etimológica contra las demás tradiciones étnicas, autóctonas, africanas, europeas y asiáticas que forman la región latinoamericana. Pues América recuerda al navegador Américo Vespucio y Latina a la etnia de los colonizadores. Entonces, los demás pueblos fueran excluidos desde el origen del proyecto de nominación de esta región de colonización. Al contrario, la heterotopía América Latina que se expande por la crítica descolonial se legitima necesariamente por el compromiso de incluir a todos los grupos identitarios, étnicos, culturales y religiosos, en un mismo contexto de significaciones compartidas (MARTINS, 2012, p. 14).
\end{abstract}

Os avanços chegaram, independências e revoluções aconteceram, mudanças e transformações giram em torno dos países latino-americanos, entretanto, a pobreza, a fome, o analfabetismo - a injustiça e desigualdades sociais - ainda caracterizam essa parcela da humanidade.

O colonialismo teve como uma de suas ações fundamentais a homogeneização de sociedades tradicionais, a indigenização, e ampliou-se na construção dos Estados-Nacionais. O processo homogeneizador resultava em diversas medidas que visavam diminuir a força cultural dessas sociedades de forma que as mesmas ficassem mais suscetíveis e receptivas ao projeto civilizatório das grandes metrópoles. Tal projeto logrou vários sucessos, expandiu-se consideravelmente - diversas etnias foram agrupadas em uma só categoria, a de índio - e acabou por enraizar-se, o sistema colonial afetou todos os componentes dessas sociedades. Do seu enraizamento e massificação surgiu o colonialismo interno ${ }^{7}$, a reprodução dos modos de colonização, no seio das (ex)colônias, através da subjugação, dominação, escravidão ou através do sistema patriarcal imposto às mulheres dessas sociedades (CUSICANQUI, 2010b).

O sistema de gênero das sociedades que foram colonizadas está vinculado ao sistema de gênero colonial, isto é, seu alicerce são as relações culturais de gênero advindas do processo civilizatório, no qual há uma hierarquia entre homens e mulheres - estas duas categorias fechadas não abriam espaço para debates e discussões acerca do terceiro gênero,

\footnotetext{
7 O conceito de Colonialismo interno foi extraído de Pablo González Casanova. A definição do colonialismo interno está originalmente ligada a fenômenos de conquista, em que as populações de nativos não são exterminadas e formam parte, primeiro do Estado colonizador e depois do Estado que adquire uma independência formal, ou que inicia um processo de libertação, de transição para o socialismo, ou de recolonização e regresso ao capitalismo neoliberal. Os povos, minorias ou nações colonizadas pelo Estado-nação sofrem condições semelhantes às que os caracterizam no colonialismo e no neocolonialismo em nível internacional (CASANOVA, 2007).
} 
gays, lésbicas, etc. Essa hierarquia foi estendida para as categorias raça, etnia e classe. A situação das mulheres colonizadas se distingue pelo fato de terem sofrido e sofrerem com a colonização das grandes metrópoles e também por sofrerem o colonialismo interno. Ou seja, essas mulheres foram condicionadas a um padrão de comportamento e de vida distante de sua cultura, e esse padrão foi [é] reproduzido na nova sociedade imposta pelo Ocidente (CUSICANQUI, 2010a).

Existem indícios de que nas sociedades andinas pré-hispânicas as relações de gênero eram baseadas em estruturas organizacionais que resultavam em relações de gênero um tanto quanto igualitárias - como uma coexistência complementar e não antagônica (CUSICANQUI, 2010a). Existiam assimetrias nas relações, porém estas não se constituíam de forma tão estanque como no sistema colonial e patriarcal de gênero que pontua especificamente o lugar na sociedade do homem - que vai se consolidando como público - e o da mulher realocada no âmbito privado.

Com a chegada dos colonizadores houve uma mudança na forma de se relacionar das sociedades tradicionais. As diferenças do outro ficaram mais evidentes, resultando em intenso distanciamento das etnias, isso gerou um mecanismo de exclusão, no qual se aponta o outro como um ser não social - um outro inferior. Nesse momento acontece o encontro do colonialismo com o patriarcalismo que juntos passam a ser um meio de dupla exclusão, pois o gênero passa a ser considerado como uma variável maniqueísta de diferenciação, no qual o sexo feminino é tido como o subalterno, em uma visão que o torna inferior.

As mulheres das sociedades tradicionais tornam-se objetos perante o novo sistema de gênero imposto pelo colonialismo, as mesmas foram cedidas - de acordo aos relatos e visão romantizadora dos contadores de história - aos colonizadores como presentes em gesto de benevolência e de boas vindas aos chegados de terras distantes. Esse novo papel social imposto às mulheres gerou danos reais e profundos para estas, e para a sociedade como um todo, devido à reestruturação nos modos de convivência, de relacionamento e de organização, tanto em seu círculo como para com as outras sociedades. Dessa prática de oferecimento das mulheres aos colonizadores que em sua maioria se deram por meio de estupros, surgiram os mestiços que sofriam duplamente com a reformulação da organização societal, pois não eram nem indígenas nem europeus, se constituíram como diferentes - o meio termo entre duas 
realidades completamente separadas - algo que no encontro de tradicionais e colonizadores submetido a uma lente conservadora foi irreversivelmente posto como inferior ${ }^{8}$.

Essa exclusão que se aplica[va] a determinados seres foi ainda mais intensa no que se refere às mulheres e principalmente às mestiças, ou seja, às mulheres dessas sociedades, que a partir do sistema colonial de gênero já haviam sido colocadas como inferiores, passaram a ter mais elementos que as diferenciassem negativamente dos demais componentes da sociedade. As mulheres mestiças, e também os mestiços, passaram a ocupar os estratos mais baixos das sociedades coloniais, mediante rejeição de pertença étnica e dos cidadãos europeus, diante disso resta às mestiças e aos mestiços o "caminhar só e com suas próprias pernas", gerando assim novas formas de sobreviver à realidade que os cercam. Com a exclusão e separação de uma parcela da sociedade, o sistema colonial de dominação vai se enraizando e se fortalecendo, criando com isso ramificações da subjugação. Como explica Cusicanqui:

[...] hay otras caras del proceso: la violencia conyugal crece en espiral, al intensificarse las presiones aculturadoras sobre las familias, donde la autoridad y el modelo pasan a ser regidos por la imagen masculina aculturada, que reniega de lo suyo a través del desprecio por su propia compañera o madre. Se produce así un doble proceso de colonización, cultural y de género, que ha de marcar a hierro a todas las generaciones del "mestizaje colonial andino" (CUSICANQUI, 2010b, p. 194). ${ }^{9}$

O processo civilizatório empreendido pelas sociedades evoluídas da Europa na América Latina se desenvolveu no sentido de fragilizar o modo de vida dos latinoamericanos. Com isso os costumes e modo de organização societal europeu/ocidental foram sendo infiltrados nas sociedades tradicionais de modo a mostrar a essas sociedades, tidas como não evoluídas, que o outro mundo era melhor no viver, no vestir, no falar, no desenvolvimento econômico e assim por diante. Para essa apresentação e ensinamento do mundo melhor foi necessária à imposição, uma vez que - na visão eurocêntrica - os não evoluídos não tinham ciência do que era bom e correto. O capitalismo - também patriarcal foi outra ferramenta de dominação e subjugação utilizada pelo ocidente que afetou de modo

\footnotetext{
${ }^{8}$ Concepção e interpretação de Silvia R. Cusicanqui acerca da realidade andina, essa categorização de mestiço como o mais marginalizado não se aplica, por exemplo, à sociedade brasileira, caracterizada pela noção da democracia racial e da mestiçagem como um elemento unificador da nação.

${ }^{9}$ Tradução livre: [...] existem outras caras do processo: a violência doméstica cresce em espiral com o aumento da pressão cultural sobre as famílias, na qual a autoridade e o exemplo passam a ser regido pela figura masculina, que renega e despreza sua companheira ou sua mãe. Se produz assim, um duplo processo de colonização e de gênero, que marca a ferro todas as gerações da "mestiçagem colonial andina" (Cusicanqui, 2010b, p. 194).
} 
sem igual às mulheres, indígenas e afrodescendentes, tornando-as maioria nas classes pobres dos países latino-americanos ${ }^{10}$.

A luta e o movimento feminista das mulheres colonizadas/subalternas ${ }^{11}$ vão além da bandeira de reorganização da divisão social do trabalho, levantada pelas correntes feministas tradicionais, a principal problemática das mulheres colonizadas se constitui nas questões de distribuição do exercício de poder nos mais variados espaços da sociedade e do Estado (CUSICANQUI, 2010a). Essa luta das feministas colonizadas/subalternas combate o projeto homogeneizador ocidental/eurocêntrico, as mesmas buscam acabar com a dominação e subjugação cultural que impõe um sistema de organização social patriarcal, que parece cada vez mais inferiorizar as mulheres, bem como as diferenças étnicas. Essas mulheres lutam por suas identidades, sejam elas culturais, étnicas ou corporais, as mesmas buscam o seu espaço na sociedade como um todo - não apenas no espaço de trabalho - seja no âmbito privado e também no público. As subalternas lutam pelo direito de construir, desenvolver e transformar a sociedade onde vivem, ensejam por um sistema de gênero que fomente cada vez mais a igualdade de posições e a complementaridade.

O movimento feminista boliviano gerou várias contribuições para as novas gerações de feministas, uma delas foi o:

[...] programa que intentó descolonizar y resignificar el lenguaje, la palabra, para que ésta deje de ser el talismán del conquistador y se convierta en medio de comunicación y en espacio de ejercicio de la libertad. (CUSICANQUI, 2010b, p 199)..$^{12}$

As mulheres colonizadas/subalternas buscam resgatar ou gerar uma relação harmoniosa - não condicionada - entre mulheres e homens, uma relação que seja baseada na coletividade e no respeito às diferenças. Essa corrente feminista - latino-americana contempla as diferentes raças, etnias e culturas, as maneiras de coexistir como humanas e humanos, sem exceções, uma vez que são essas diferenças que as constituem, as consolidam e as desenvolvem. Os ensinamentos dessa corrente com suas especificidades podem contribuir

\footnotetext{
${ }^{10}$ Opinião embasada na revisão bibliográfica e leituras dos textos de Silvia Rivera Cusicanqui.

${ }^{11} \mathrm{O}$ conceito de "subalterno" utilizado no artigo baseia-se nas definições utilizadas por Gayatri C. Spivak e Antonio Gramsci. Para Spivak, subalternos são [...] "as camadas mais baixas da sociedade constituídas pelos modos específicos de exclusão dos mercados, da representação política e legal, e da possibilidade de se tornarem membros plenos no estrato social dominante" (Spivak, 2010, p. 13-14). Para Gramsci os subalternos são "aqueles que, [...], vivem "ás margens da história", [...] "subalternos" são, em sentido geral (econômico, cultural e político), os outros, privados de identidade e reduzidos a subordinação aos detentores do poder domínio e hegemonia na sociedade [...] (Baratta, 2011, p. 153-154).

${ }^{12}$ Tradução livre: [...] programa que tentou descolonizar e ressignificar a linguagem, a palavra, para que esta deixe de ser o talismã do conquistador e se converta em meio de comunicação e espaço de exercício de liberdade (CUSICANQUI, 2010b, p 199).
} 
para fomentar o projeto que busca desenvolver uma pluralidade de identidades femininas e ao mesmo tempo ampliar espaços de convivência entre o(a)s diferentes sejam ele(a)s mulheres, homens, indígenas ou classes subalternas (CUSICANQUI, 2010a).

No cenário de lutas, debates e projetos para construir uma América Latina soberana, democrática e com oportunidades iguais para todos os latino-americanos as questões e temas feministas que aqui se constituem possuem um caráter diferente, carregam especificidades em lidar com as questões de gênero. Nesse contexto de lutas e levantes contra os opressores, através de uma perspectiva crítica, o feminismo latino-americano denuncia as várias formas de subjugação e opressão sofridas pelas mulheres. Os homens latino-americanos também passaram pelo projeto de dominação colonial, porém não do mesmo modo que as mulheres, a eles foram conferidos privilégios resultantes de sua masculinidade. Fortalecidos pelo patriarcalismo, colocam as mulheres em níveis inferiores na sociedade. Nem mesmo em questão de direitos pode ser equiparada, pois os homens são os condutores da humanidade e, por isso, possuem mais direitos e maior liberdade - naturalizando assim as formas de opressão e exclusão das mulheres.

Deste modo evidencia-se a luta das latino-americanas contra barreiras e subordinações advindas do colonialismo, bem como enfrentam a exclusão - seja baseada no gênero ou em outras formas de discriminação das classes subalternas - e formas de [re]colonização [re]produzidas por sua própria sociedade. As correntes feministas destacam a importância e implementação de políticas para defesa e garantia dos direitos das mulheres, assim como para as classes subalternas da sociedade. Tais políticas e ações devem ser desenvolvidas pensando nas especificidades das mulheres - indígenas, negras, brancas, pobres, deficientes, lésbicas, bissexuais, transgêneras, etc. - para buscar e alcançar resultados satisfatórios.

\section{Marcha Mundial das Mullheres na contemporaneidladle ${ }^{13}$}

Os movimentos sociais são mecanismos de articulação e mobilização social que atuam para construir alternativas a determinadas realidades, de maneira simplificada tais movimentos podem ser definidos como organizações coletivas que se articulam e agem para alcançar determinado objetivo (BRINGEL;FARELO, 2008, BRINGEL;MUÑOZ, 2010).

\footnotetext{
${ }^{13}$ Texto construído a partir de leituras dos documentos e textos nos sites, e das chamadas e convites para as ações, mobilizações e organização da MMM no Brasil, bem como em outros textos e artigos sobre movimentos sociais e feminismo.
} 
Esse coletivo se constitui e se firma sócio politicamente objetivando a emancipação. Fica evidente o porquê das palavras mais recorrentes nos estudos sobre movimentos sociais e na prática dos movimentos sociais serem: direitos, democracia, cidadania, formação de identidade, identidade cultural, racionalidade e subjetividade. Os diferentes coletivos de movimentos sociais com as mais variadas bandeiras são criados, geridos e fomentados dentro dos limites territoriais de seu país de origem, entretanto com o marco da globalização ocorreram mudanças na dinâmica dos movimentos sociais.

A mobilização política ou articulação político-social foi absorvendo as influências e demandas internacionais, bem como se inseriu nas ações político-sociais transnacionais, com isso a sociedade civil articulada através dos movimentos sociais passou a dividir com os Estados e as Organizações Internacionais espaço no cenário internacional. Essa nova dinâmica intensificou-se através dos protestos de Seattle (em 1999) ${ }^{14}$ e do surgimento do movimento antiglobalização (BRINGEL; MUÑOZ, 2010).

As ações coletivas internacionais geraram resultados, sendo a criação do Fórum Social Mundial ${ }^{15}$ um dos grandes impactos do movimento antiglobalização. A organização do fórum visava elaborar e expor propostas para o movimento que cada vez mais extrapolava as fronteiras dos Estados, além de possibilitar trocas de conhecimentos e aprendizados. Uma das características mais marcantes dos movimentos sociais transnacionais se configura na concentração de diferentes movimentos sociais sejam eles estaduais e/ou nacionais que unem as demandas locais com as globais. No espaço de articulações, propostas e troca de experiências do Fórum Social Mundial, a Marcha Mundial das Mulheres teve um impulso a mais para se expandir e se solidificar.

A Marcha Mundial das Mulheres (MMM) é um movimento social feminista influente, complexo, heterogêneo e com elementos bastante contemporâneos. A Marcha trabalha e se desenvolve em rede de forma a legitimar sua atuação e ações frente ao Estado, a outros grupos/movimentos e ao cenário internacional (PINGRET, 2013).

A MMM teve como embrião uma manifestação que reuniu, no ano de 1995 , cerca de 850 mulheres em uma marcha de duzentos quilômetros em Quebec - Canadá. Tais mulheres

\footnotetext{
${ }^{14}$ Série de protestos ocorridos na cidade de Seattle em 1999 contra a Cúpula da Organização Mundial do Comércio (OMC) que acontecia naquela cidade, marcando assim a difusão do movimento antiglobalização (Bringel \& Muñoz, 2010. p. 29).

${ }^{15}$ O Fórum Social Mundial se configura como uma das vertentes do movimento antiglobalização, o fórum possui um caráter reformista, focando-se na reforma da globalização neoliberal no sentido de pontuar questões sociais na agenda política rumo a uma justiça global (Bringel \& Muñoz, p. 31).
} 
simbolicamente pediam "pão e rosas" em uma crítica categórica ao sistema capitalista. Essa mobilização logrou êxitos como aumento de salário mínimo, aumento de direitos para mulheres imigrantes, apoio à economia solidária e principalmente o fortalecimento das mulheres participantes enquanto coletivo. Em seu formato atual - de grande mobilização e organização internacional - a Marcha ocorreu pela primeira vez no ano 2000, tendo como principais eixos o combate à pobreza e à violência. A bandeira central era "2000 razões para marchar contra a pobreza e a violência sexista". Por meio dessa mobilização, cobravam-se ações e políticas públicas que gerassem condições dignas de vida para as mulheres. As ações do primeiro ano de marcha se iniciaram no dia 8 de março - Dia Internacional da Mulher - e se encerraram dia 17 de outubro do mesmo ano.

Sua primeira edição contou com aproximadamente quinhentos grupos de pessoas de 159 países e estimulou milhares de mulheres ao redor do mundo a participarem de eventos com a mesma finalidade. Nesse ano, o coletivo MMM produziu e entregou à Organização das Nações Unidas um documento que elencava 16 pontos reivindicatórios assinado por cinco milhões de pessoas de diferentes localidades.

Na marcha seguinte, no ano de 2005, formulou-se a Carta Mundial das Mulheres para Humanidade, na qual se apresentava diversas alternativas para a reorganização do mundo pautada na igualdade, na paz, na liberdade, na diversidade e na cultura. Nesse ano foi tecida a grande "Colcha Mosaico de Solidariedade", que simbolizava a coletividade da Marcha, uma vez que contou com pedaços de retalho de diversos países.

Em 2010, terceira edição da MMM, um dos eixos centrais foi o centenário do Dia Internacional da Mulher resultando em muitas formas de ações e temas para os diferentes coletivos ao redor do mundo que cada vez mais se agrupavam e davam força a MMM. A bandeira principal da $3^{\mathrm{a}}$ edição foi "Seguiremos em marcha até que todas sejamos livres" tendo como diretrizes basilares: contra a tirania do patriarcado e do livre mercado, pela autonomia econômica das mulheres, por um mundo sem violência contra as mulheres, contra a privatização da natureza e dos serviços públicos, paz e desmilitarização (PINGRET, 2012, p. 24). Um ponto importante a se destacar nesse ano foi o enfoque que se deu à situação da mulher em questões de conflitos armados e na busca pela paz e boas relações sociais.

Além das mobilizações periódicas, organizando-se em núcleos e comitês em diferentes estados e cidades, a MMM no Brasil conta com a participação de mulheres advindas de outros 
coletivos sócio-políticos e de mulheres que na sua individualidade se unem ao comitê ou núcleo de sua cidade ou estado. O país se destaca como um dos principais espaços de articulação e organização da Marcha.

As pautas e eixos da MMM são norteados pela organização, mobilização e agrupamentos das mulheres em sua totalidade. Entre as ideias e convicções da Marcha estão: a defesa da visão das mulheres como sujeitos ativos na transformação de suas vidas e a necessidade de superar o sistema capitalista patriarcal, racista, homofóbico e destruidor do meio ambiente. Os anos de 2000, 2005 e 2010 marcaram o desenvolvimento, a consolidação, a internacionalização e maior abrangência da MMM.

Entretanto, a aglutinação dos problemas enfrentados pelas mulheres por um coletivo que prega totalidade e igualdade e que não evidencia de forma precisa como lida com o enorme grau de diferenças entre as mulheres pode acarretar em uma homogeneização de demandas. Tal universalização poderia apagar as diferenças das mulheres, colocando-as em uma só categoria. Essas diferenças não se caracterizam pela inferioridade, mas sim pelas especificidades que cada uma carrega em seu acumulo cultural, vivência, história e desejos.

A Marcha Mundial das Mulheres não dialoga de forma explícita e aprofundada com temas sensíveis às mulheres colonizadas, por exemplo, a condição de dupla subjugação das latino-americanas desenvolvida no encontro entre colonialismo e patriarcalismo, ou mesmo as vertentes discriminatórias desse encontro. Outro ponto importante a se destacar é a não proximidade do movimento em relação à categoria raça enquanto uma construção ideológica criada para oprimir. Nesse caso a situação das mulheres negras, por exemplo, é extremamente específica e sensível.

\section{Figura 1: Reuniões e plenárias estaduais da Marcha Mundial das Mulheres no Brasil}
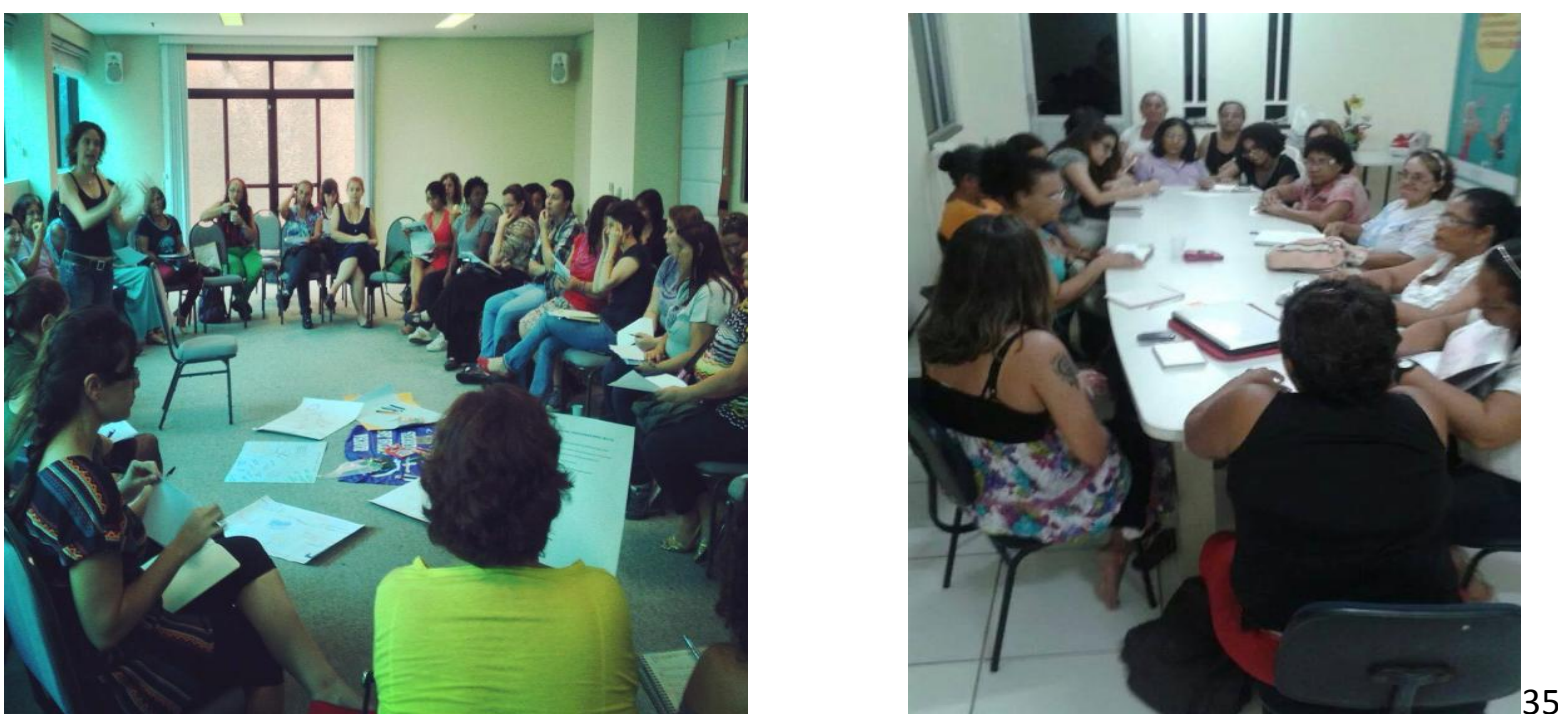
Fonte: Fotos retiradas da página do Facebook Marcha Mundial das Mulheres. Disponível em: <https://www.facebook.com/marchamundialdasmulheresbrasil/photos_stream >.

Nas imagens acima se visualiza a baixa representação das mulheres negras assim como as indígenas nas plenárias e reuniões que desenvolvem e coordenam as ações da Marcha, dentro desse movimento encontramos as mulheres negras - e as indígenas em menor número - majoritariamente nas ruas e nas ações propriamente ditas, mas é difícil encontrar a fala ou participação direta dessas mulheres no cerne das ações.

Figura 2: Reunião e ações nacionais da Marcha Mundial das Mulheres no Brasil
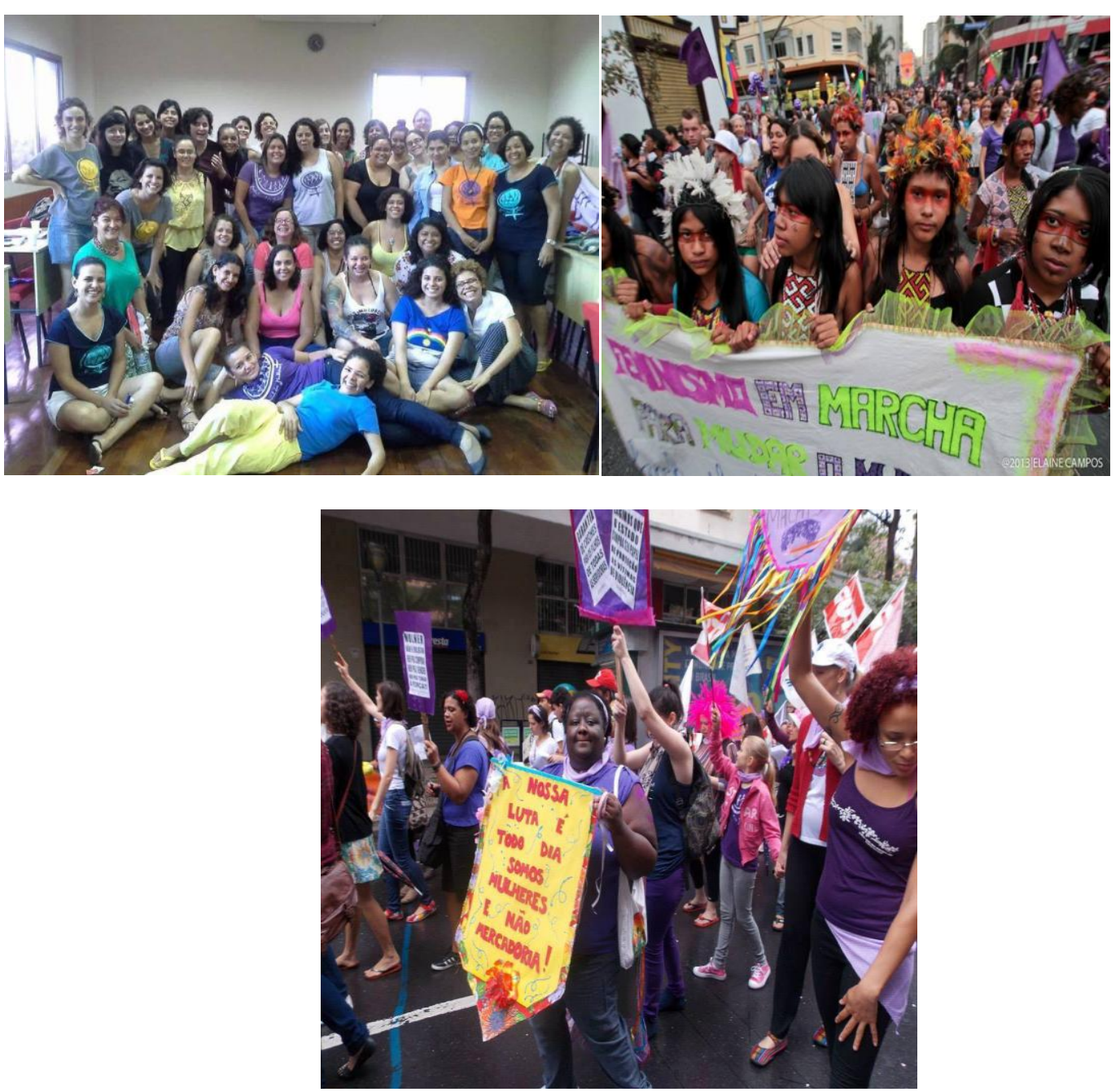

Fonte: Fotos retiradas da página do Facebook Marcha Mundial das Mulheres. Disponível em: <https://www.facebook.com/marchamundialdasmulheresbrasil/photos_stream >. 
Mesmo nos espaços de reuniões e plenárias nacionais percebe-se a baixa representatividade das mulheres negras e mais ainda das mulheres indígenas. Através do distanciamento das negras e indígenas das esferas de articulação e criação de pautas e demandas, corre-se o risco de deixá-las de fora do processo de emancipação em um sentido amplo e igualitário.

A Marcha, criada em um país ocidental capitalista e anglo-saxão, que critica fortemente a divisão social do trabalho, a distribuição de renda, as imposições do livre mercado e a violência contra mulher, não evidencia seu comprometimento com os problemas resultantes do colonialismo, que ainda é uma realidade presente e enraizada na América Latina, bem como em outras porções do Sul global. A história da colonialidade e seus diferentes tipos de violência não possuem espaço contemplado no desenvolvimento de mobilizações, ações e formulações de bandeiras na MMM.

Nas abordagens sobre mulheres negras, pobres e/ou indígenas, sempre tidas como assuntos que necessitam de uma atenção especial, elenca-se a larga distancia a ser alcançada até a igualdade, principalmente nos casos das mulheres marginalizadas, mas não explicitam ou pontuam em que nível está tal desigualdade (NOBRE; FARIA, 2003) ${ }^{16}$. Como tal projeto rumo à igualdade pode não adquirir face homogeneizadora? Ou ainda tornar mais invisíveis as subalternizadas?

Faz-se necessário saber até que ponto essa coletivização mais abrangente transnacional - das demandas feministas e das mulheres expressa e carrega as vozes das mesmas, ou acabará por se tornar mais um instrumento da colonialidade e do colonialismo interno.

Ainda que a Marcha Mundial das Mulheres seja feita por mulheres e para mulheres, se faz necessário um diálogo mais íntimo entre esse movimento e as questões da colonialidade, do pós-colonialismo e da decolonização, bem como uma maior aproximação para com as especificidades das mulheres.

\section{Considerações finais}

Esse é um primeiro resultado de uma pesquisa que está em andamento. Ainda em caráter exploratório, mais do que conclusões, apresentam-se sensações acerca da atuação da

\footnotetext{
16 Opinião embasada nos documentos e textos das chamadas e convites para as ações, mobilizações e organização da MMM no Brasil.
} 
MMM. O próximo passo é coletar materiais e entrevistas mediante pesquisa de campo de forma a melhor fundamentar as proposições aqui apresentadas. Partindo do estudo da ativista boliviana-aymara Silvia Rivera Cusicanqui, entende-se que uma das principais características da América Latina é a dupla exploração empreendida pelo colonialismo e pelo patriarcado. Nas RI ainda são poucas as vozes que destacam a colonialidade de gênero e se dispõem a compreender o pensamento militante latino-americano. Nesse sentido, espera-se contribuir para a difusão dessas ideias e suas possibilidades em interpretar a realidade e o ativismo social.

A Marcha Mundial das Mulheres, um movimento social contemporâneo, fluído, heterogêneo e complexo que atua no sentido de condensar outros movimentos de diferentes bandeiras se constitui como um ambiente extremamente importante para a articulação das mulheres e suas demandas.

Entretanto, as temáticas mais trabalhadas e divulgadas pelas MMM são exportadas e incorporadas à realidade latino-americana com o mínimo de adequação e diálogo com as especificidades dessa realidade. Divisão sexual do trabalho, salário mínimo, aborto, mercantilização do corpo feminino e o autoritarismo do capitalismo, por exemplo, são as principais bandeiras que impulsionaram as lutas dos movimentos sociais europeus durante o século XX. Se os problemas elencados a essas temáticas cabem a nós? Sim, sem sombra de dúvidas. Porém a realidade das mulheres que passaram pelo colonialismo é outra, as latinoamericanas são diferentes e essa diferença se configura como parte de suas identidades.

O modo como o sol irradia e dá energia para uma plantação na França ou Alemanha não fornecerá os mesmos resultados quando irradiado nos campos da Argentina ou Colômbia, bem como as implicações e regulamentações de uma lei não serão as mesmas em diferentes lugares do globo. Os problemas sejam eles econômicos, sanitários, sociais, políticos, etc. que ocorrem na América Latina não tem as mesmas implicações - nem mesmo entre seus países que teriam na Europa. O clima é diferente, os idiomas são diferentes, as culturas são diferentes e, principalmente, as relações sociais se constituem de maneira muito distinta.

Há uma preocupação nesse artigo acerca da possibilidade da MMM inserir pautas eurocêntricas nas localidades latino-americanas. Para evitar tal aprisionamento, próprio do feminismo branco, faz-se necessário escutar e reivindicar a partir da diversidade constituinte da unidade das relações coloniais ainda vigentes. O imperialismo é tratado apenas em sua vertente econômica e de forma generalizada. A Marcha bate forte e fala alto quando se trata 
de combater o capitalismo, mas suas vozes parecem diminuir ou mudar de tom quando se aborda a questão das diferenças entre as mulheres - não em sentido inferior - mas no que tange as desigualdades sociais, raciais/étnicas, culturais, etc.

O preconceito, a violência, a discriminação e a desigualdade das mulheres por vezes são tratados como uma coisa só, com um mesmo padrão de comportamento tanto por parte das mulheres quanto dos homens. Quando se aborda - de maneira sucinta e muito breve - o assunto mulheres negras, pobres e/ou indígenas explicitam de maneira equivocada a atenção “especial” que esse assunto requer.

A América Latina por vezes é tratada como uma extensão da América do Norte, mas que ainda não se desenvolveu e que necessita cuidar de alguns pontos de maneira especial para que haja uma padronização final das Américas e assim todos os povos sejam Americanos, passando por cima de toda a pluralidade que foram e que são as Américas. A própria diversidade do feminismo parece ser incluída em um projeto maior de igualdade. As relações de gênero na América Latina carecem de um olhar pontuado, uma vez que mesmos os intelectuais - em sua grande maioria - que estudam e se articulam em busca de uma emancipação latino-americana deixam de lado as questões de gênero, evidenciando a força da exclusão das mulheres, bem como as debilidades presentes nos estudos acerca das relações de gênero nessas sociedades.

A Marcha Mundial das Mulheres foi e é um espaço vital de luta e empoderamento para mulheres, esse movimento reivindica e trabalha por políticas públicas que possam gerar transformações reais nas sociedades. Entretanto, é necessário que nessa esfera de poder feminino se construa um maior diálogo e também debates com temas sensíveis ao feminismo pós-colonial. Como citado no artigo, o feminismo boliviano é um exemplo de luta que respeita diversidade e inclui múltiplas identidades.

Possivelmente, o maior desafio a se propor à Marcha seja o desenvolvimento de uma plataforma que atenda a grande diversidade e diferentes visões e concepções de mundo das componentes do movimento.

\section{Referências bibliográficas}

AUCÍA, Anália. Estrategias, alianzas y desafíos feministas en materia de litigio Internacional - La experiencia de litígio de Cladem, 2012. Disponível em 
<http://www.feminicidio.cl/jspui3/bitstream/123456789/434/1/Estrategias_alianza_desafios_li tigio_internacional.pdf >. Acesso em: 03 fev 2013.

BARATTA, Giorgio. Antonio Gramsci em contraponto: diálogos com o presente. Tradução de Jaime Clasen. São Paulo: Editora Unesp, 2011. 380p.

BRINGEL, Breno; ECHART, Enara. Movimentos Sociais e Democracia: os dois lados das "fronteiras". Caderno CRH. Salvador: v. 21, n 54, 2008.

BRINGEL, Breno; FALERO, Alfredo. Redes Transnacionais de Movimentos Sociais Na América Latina e O Desafio de Uma nova Construção Socioterritorial. Caderno CRH. Salvador: v. 21, n 53, 2008.

BRINGEL, Breno; MUÑOZ, Enara Echart. Dez anos de Seattle, o movimento antiglobalização e a ação coletiva transnacional. Ciências Sociais Unisinos. São Leopoldo: v. 46, n 1, 2010.

CAROSIO, Alba (Orgs). Feminismo y cambio social en América Latina y el Caribe, 2012. 1era Ed. Buenos Aires: CLACSO, 2012, 272 p. Disponível em

<http://bvsde.org.ni/clacso/publicaciones/Feminismoycambiosocial.pdf>. Acesso em: 03 de fevereiro 2013.

CASANOVA, Pablo González. Colonialismo Interno - Uma redefinição. In: A teoria Marxista hoje. Problemas e perspectivas. BORON, Atílio A.; AMADEO, Javier; GONZALEZ, Sabrina. Buenos Aires: CLACSO, 2007. Disponível em: < http://bibliotecavirtual.clacso.org.ar/ar/libros/campus/marxispt/cap>. Acesso em: 05 de outubro 2014.

COSTA, Maria da Graça Silveira Gomes da; SCHWADE, Elisete. Discursos e feminismos em movimento entre a marcha mundial de mulheres e o MST. Sociais e Humanas. Santa Maria: v. 25, n 02, 2012.

CUSICANQUI, Silvia Rivera. Ch'ixinakax utxiwa : una reflexión sobre prácticas y discursos descolonizadores. Buenos Aires: Tinta Limón, 2010. 79p. [2010a]

CUSICANQUI, Silvia Rivera. Violencias (re) encubiertas en Bolivia. La Paz: Editorial Piedra Rota, 2010. [2010b]

DUSSEL, Enrique D. Cultura Imperial, Cultura Ilustrada e Libertação da Cultura Popular In: DUSSEL, Enrique D. Para uma ética da libertação latino americana III: erótica e pedagógica. São Paulo: Loyola; Piracicaba: UNIMEP. (s/d), 253- 281.

GOHN, Maria da G. Abordagens teóricas no estudo dos movimentos sociais na América Latina. Caderno CRH. Salvador: v. 21, n. 54, p. 439-455, 2008.

MARCHA MUNDIAL DAS MULHERES (MMM). Histórico. Disponível em: <http://marchamulheres.wordpress.com/mmm/>. Acesso em: 05 de agosto 2014.

MARTINS, Paulo Henrique. La decolonialidad de América Latina y la heterotopía de una comunidad de destino solidaria. Buenos Aires: Fundación CICCUS; Estudos Sociológicos Editora, 2012. 159p. 
NOBRE, Miriam; FARIA, Nalu. Feminismo em movimento: temas e processos organizativos da Marcha Mundial das Mulheres no Fórum Social Mundial. In: Revista Estudos Feministas. CFH/CCE/UFSC, volume 11, n. 2/2003.

NOGUEIRA, João Pontes; MESSARI, Nizar. Perspectivas alternativas: Feminismo e Póscolonialismo. In: NOGUEIRA, João Pontes; MESSARI, Nizar. Teoria das Relações Internacionais: correntes e debates. Rio de Janeiro: Elsevier, 2005. Cap. 8, 221-230.

PINGRET, Alexandra. A marcha mundial das mulheres no contexto dos movimentos sociais e sua construção visual (Brasil, 2000-2010). Londrina, 2012. Dissertação de mestrado - Universidade Estadual de Londrina.

PINGRET, Alexandra. Os movimentos sociais contemporâneos e a marcha mundial das mulheres. História: Debates e Tendências. v. 13, n. 1, 2013.

PINSKY, C., PEDRO, J. M. Igualdade e Especificidade. In: PINSKY, Jaime; PINSKY, Carla B. (Orgs.). História da Cidadania. São Paulo: Contexto, 2003. Cap., 266-280.

QUIJANO, Aníbal. Dossiê América Latina: Dom Quixote e os moinhos de vento na América Latina - Das linhas globais a uma ecologia de saberes. Revista Estudos Avançados. São Paulo, n 19, 2005.

SANTOS, Boaventura de Sousa. Para além do pensamento abissal. Revista Novos Estudos Cebrap. 2007, p. 71-94.

SANTOS, Milton. Por uma outra globalização: do pensamento único à consciência universal. 6. ed. Rio de Janeiro: Record, 2001. v. 27.

SODUPE, Kepa. La teoria de las Relaciones Internacionales a comienzos del siglo XXI. Bilbao: Servicio Editorial de la Universidad del País Vasco, 2003. 254p.

SPIVAK, Gayatri Chakravorty. Pode o subalterno falar? Tradução de Sandra Regina Goulart Almeida, Marcos Pereira Feitosa, André Pereira Feitosa. Belo Horizonte: Editora UFMG, 2010. 133p.

WALLERSTEIN, Immanuel. Análisis de sistemas - mundo Una introducción. México, D. F.: Siglo Veintiuno Editores, 2005. 85p. 